\title{
Comparison of Different Gases Injection Techniques for Better Oil Productivity
}

\author{
Mohammed A Samba ${ }^{1 *)}$, Yiqiang Li ${ }^{1)}$, Madi Abdullah Naser ${ }^{2)}$, Mahmoud O. Elsharafi ${ }^{3)}$ \\ Petroleum Engineering, Faculty of Engineering, China University of Petroleum-Beijing. \\ Petroleum Engineering, Faculty of Engineering, Misrata University-Libya. \\ McCoy School of Engineering, Midwestern State University, Wichita Falls, TX 76308, USA. \\ * corresponding email: mohammed_samba@yahoo.com
}

\begin{abstract}
There are many known enhanced oil recovery (EOR) methods and every method has its criteria to use it. Some of those methods are gas injection such as $\mathrm{CO}_{2}$ injection, $\mathrm{N}_{2}$ and hydrocarbon gas injection. Where the $\mathrm{CO}_{2}$ has been the largest contributor to global EOR. Gas injection can be classified into two main types; continues gas injection (CGI) and water alternating gas injection (WAG). The objective of this research is to propose initial gases injection plan of the $\mathrm{X}$ field to maximize the total oil recovery. The feasibility study of different gases to maintain pressure and optimize oil recovery have been examined on a simple mechanistic reservoir model of considerably depleted saturated oil reservoir. To maximize the total oil recovery, the simulation study was conducted on 3-phase compositional simulation model. For more optimization, a sensitivity study was conducted on the injection cycling and component ratios. A sensitivity study was also conducted on the following parameters to study their effects on the overall field's recovery such as flow rate and

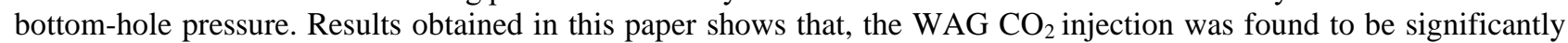
more efficient than different gas injection and continues gas injection. The oil recovery depends not only on the fluid-tofluid displacement but also on the compositional phase behavior.
\end{abstract}

Keywords: compositional model; CMG; hydrocarbon gas; miscible gas; WAG

\section{INTRODUCTION}

EOR refers to any reservoir process used to change the existing rock/oil/brine interactions in the reservoir to increase the oil recovery, and this interaction might reduce the interfacial tension, oil swelling, oil viscosity, and wettability modification. ${ }^{[1]}$ Its processes are generally classified into Miscible or Immiscible gas injection, Thermal, Chemical and others. The main objective of this paper is to emphasize the performance of Carbon dioxide $\mathrm{CO}_{2}$, Nitrogen $\mathrm{N}_{2}$, Hydrocarbon H.C and Water Alternating Gas WAG injection. Also compare the WAG displacement with the continues gas injection and obtain the optimum scenario.

$\mathrm{CO}_{2}$ injection is recently considered the first largest contribution to global EOR ${ }^{[2]}$. It vaporizes the lighter oil fractions into the injected $\mathrm{CO}_{2}$ phase and condenses into the reservoir's oil phase. This leads to two reservoir fluids that become miscible, with low viscosity, enhanced mobility, and low interfacial tension. Nitrogen $\left(\mathrm{N}_{2}\right)$ injection can be used as a substitute for $\mathrm{CO}_{2}$ in deep light to medium oil reservoirs mainly containing $C_{1}$ to $C_{7}$ components. It is applicable in both the Sandstone and Carbonate reservoirs. $\mathrm{N}_{2}$ itself an inert gas that gets miscible at very high pressure and efficiently reduces the oil viscosity and provides efficient miscible displacement ${ }^{[3]}$. Hydrocarbon (HC) miscible is like the $\mathrm{CO}_{2}$ flooding, with that the solvent is composed of a mixture of hydrocarbon components (usually $C_{2}$ to $C_{5}$ ). The injected HC solvent is usually displaced with cheaper chase leaner or inert gas like Methane or Nitrogen. ${ }^{[3]}$ 


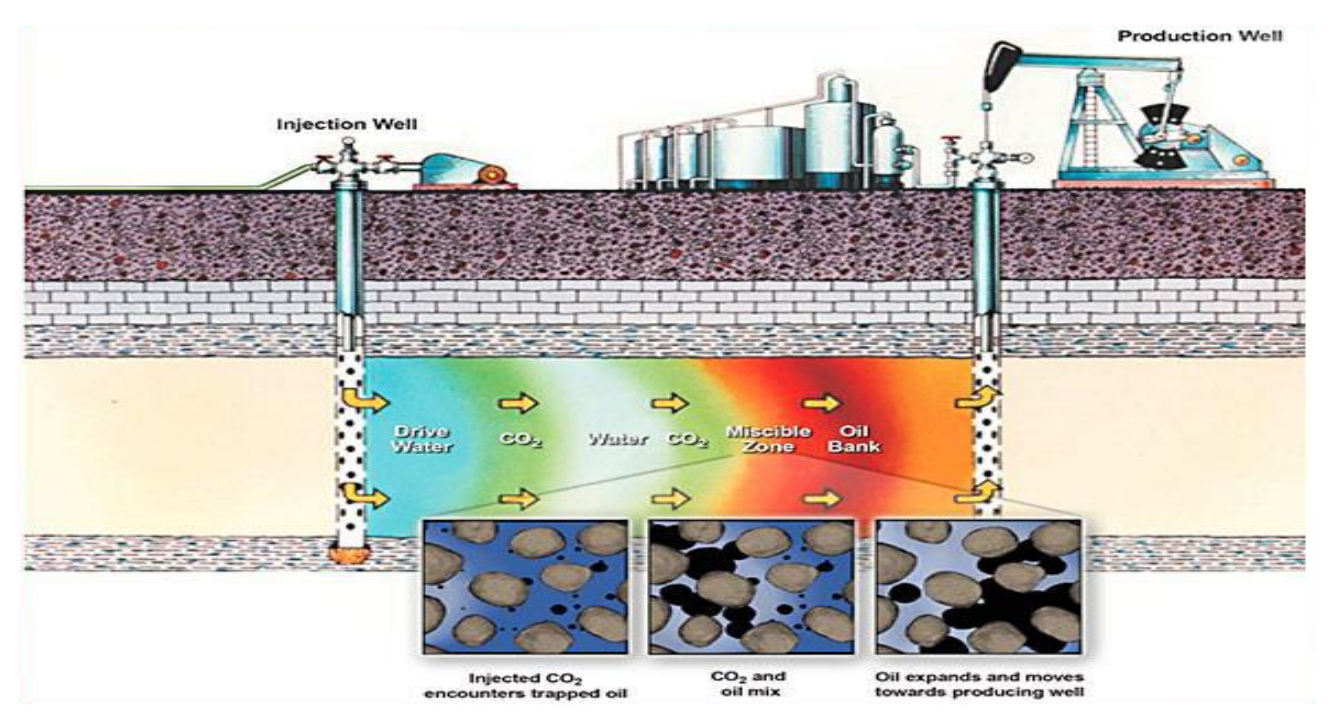

Figure 1. Schematic of the WAG process.

(Source: U.S Department of Energy, 2013) ${ }^{[4]}$

WAG is an EOR method used to produce the oil by increasing the microscopic and macroscopic sweep efficiency. This method plays an important factor to delay the breakthrough and considered as one of the best methods which enable to control the mobility ratio. This method has been applied for different type of rock, different depth, offshore and onshore successfully. ${ }^{[5]}$

\section{METHODOLOGY}

Data Preparation: Data such as thickness, porosity, relative permeability, bubble point pressure and saturations. Model Description: A 3D model with 3 Phase (oil, gas, water) has been built. A $7 * 7 * 3$ finite difference grid, as shown in Figure 2. Fluid Properties: One of the most important factors that affecting on EOR are reservoir and fluid properties, miscibility conditions, and injection technique. Oil contained the following mole presents: $\mathrm{C} 150 \%, 3 \% \mathrm{C} 3,7 \% \mathrm{C} 6,20 \%$ $\mathrm{C} 10.15 \% \mathrm{C} 15$. and $5 \% \mathrm{C} 20$. Obviously, these compositions represent an extremely light oil. Also, the injection of hydrocarbon gas has been recommended based on the company's report and the contract gas sell already done with another country. The injection well may inject $\mathrm{CO}_{2}$, Enriched Gas Mixture (HC) $(77 \% \mathrm{C} 1,20 \% \mathrm{C} 3,3 \% \mathrm{C} 6), 100 \% \mathrm{CO}$, WAG and $\mathrm{N}_{2}$. The simulation is set to run for 15 years.

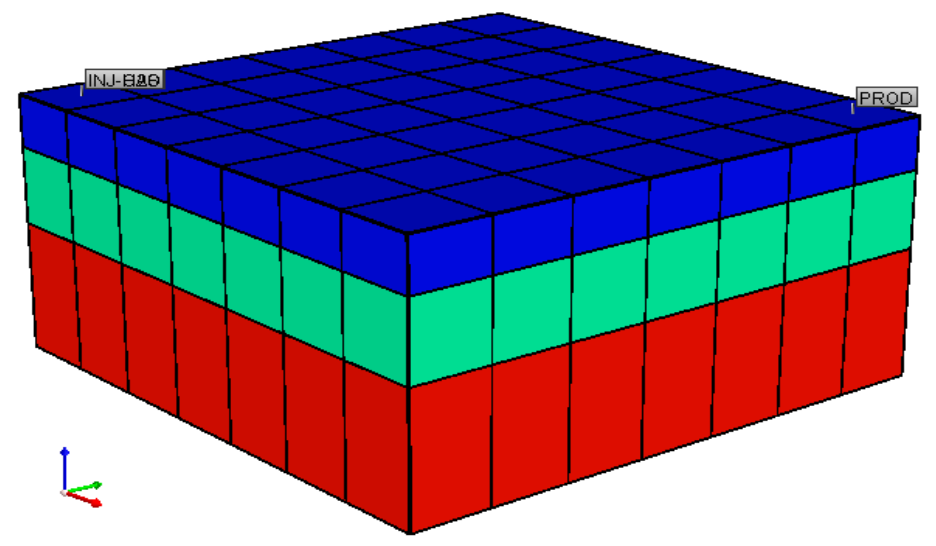

Figure 2. Grid Formation (top view).

\section{RUN SENSITIVITY ANALYSIS:}

\section{1- Different Gas Injection}

In this case 3 different types of gases will be run: $\mathrm{CO}_{2}$, hydrocarbon gas, $\mathrm{N}_{2}$ gas with same scenarios parameters. Then, the best gas injection type that have high recovery factor will be choose. 


\section{2- Injection Rate}

The maximum injection pressure should be below the fracture pressure. All the values of the injection rates (equivalent pressure below the fracture pressure). The total pore volume for this field is $3.6750 \mathrm{E}+08 \mathrm{ft}^{3}$. The gas rate will be included five flow rates: 5144, 7202, 10289, 12347 and $15434(\mathrm{Mscft} / \mathrm{d})$.

\section{3- Bottom Hole Pressure}

Sensitivity bottom hole pressure will do with the consider the reservoir pressure above the minimum miscibility pressure. The variation of the bottom hole pressure is $(200,400,600,800,1000,1200,1500$ and 2000 psi) while the flow rate will be fixed based on the previous scenario "Sensitivity Analysis of Bottom hole Pressure".

\section{4- WAG Ratio}

Sensitivity analysis will be conducted for the same gas injection rate, but different water injection rate. The variation of WAG ratio such as $1: 1,1: 2,1: 4,2: 1,3: 1$ and $4: 1$.

\section{5- WAG Cycle}

WAG cycle will conduct for duration: 6 mounts, 1 year, 1.5 year, 2 years, 2.5 years, 3 years, 4 years, and 5 years.

\section{RESULTS AND DISCUSSION}

Based on figure 2, has been noticed that the cross-sectional grid structure of the reservoir is very homogeneous in $3 \mathrm{D}$ and there are two wells are drilled (one injector and one producers).

Sensitivity Analysis for Gas Injection Types: Figure 3 shows the recovery comparison for all gas injection. $\mathrm{CO}_{2}$ has the best oil displacement process with recovery up to $63 \%$, and the project is lasting 15 years. Whereas hydrocarbon gas injection has the second highest recovery factor around $56 \%$ for the same period. While the nitrogen injection is found as least oil recovering process and it recovered about $31 \%$.

Sensitivity Analysis for Flow Rate: Table 1 shows the flow injection rate is direct proportional with the recovery factory. $15434 \mathbf{M s c f t} / \mathbf{d}$ has been chosen as the best injection rate that will give higher recovery factor.

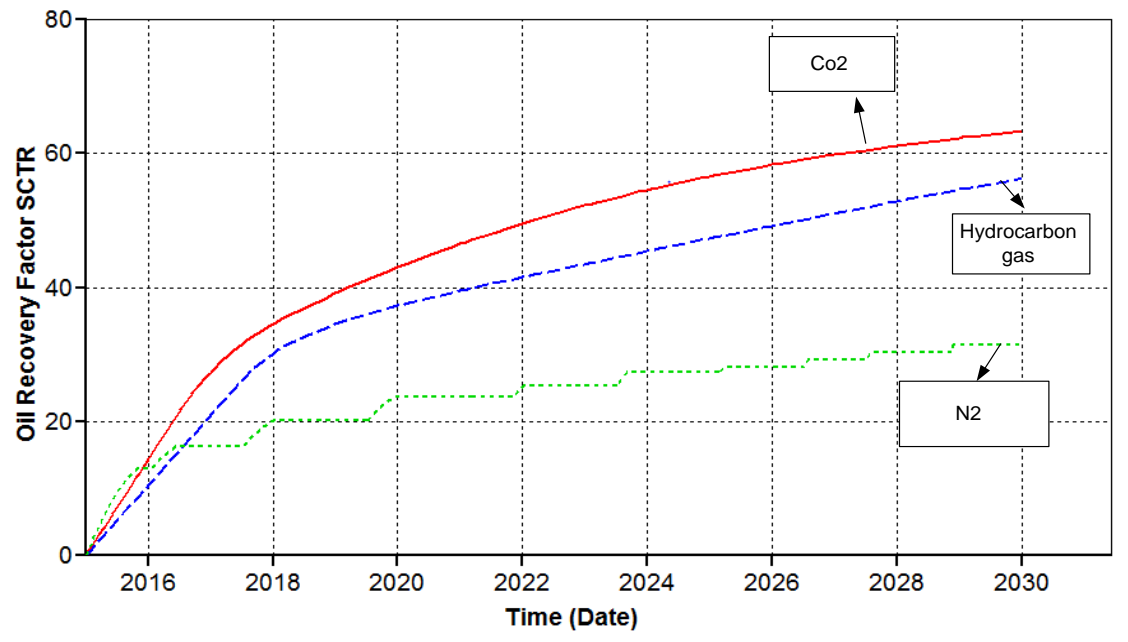

Figure 3. Variations of Different Gas Types.

Table 1. Results Of Sensitivity Analysis for Flow Rate.

\begin{tabular}{|c|c|c|}
\hline Scenario & Surface gas injection rate (Mscft/d) & Recovery factor \\
\hline 1 & 5144 & 50.8 \\
\hline 2 & 7202 & 56.4 \\
\hline 3 & 10289 & 63.4 \\
\hline 4 & 12347 & 68,4 \\
\hline 5 & 15434 & 74.4 \\
\hline
\end{tabular}


Sensitivity Analysis for Bottom Hole Pressure: BHP is one of the most important factors effecting on well productivity estimation. As the BHP increase, the production rate decreases. In the default model, the BHP was set to be 1000 psi for the producer, and it resulted a recovery factor of $75 \%$. Then, the BHP was changed to different values until 2000 for the producer well. Based on the following results. The gain is not very huge, except at 1500 psi provides high recovery factory, the gain is very huge compare with other values of the bottom hole pressure as shown in the table 2 .

Sensitivity Analysis for WAG Ratio: WAG ratio could be designed for two main reasons, the first reason based on the mobility control and the second for economic purposes. Table 3 shows the oil recovery is not direct proportional with water injection rate. The results of recovery while injecting water at different values with alternative $\mathrm{CO}_{2}$ injection was at a fixed gas rate $15434 \mathrm{MScf} / \mathrm{D}$ with the ratio of 1:1, 1:2, 1:4, 2:1. 3:1, 4:1 with fixed injection cycle (1 year). Among all the 7 selected sensitivity cases for the cycle and injection rate ratios water injection with 15000 bbl/D has given the best recovery for long lasting at the injection ratio of 3:1.

Sensitivity Analysis for WAG Cycle: Table 4 shows the oil recovery for different WAG cycle. Among all the 7 selected sensitivity cases for the different cycles at constant WAG ratio 3:1, the higher recovery factor was at cycle of 5 year.

Table 2. Results of Sensitivity Analysis for Bottom Hole Pressure.

\begin{tabular}{|c|c|c|c|}
\hline Scenario no & Bottom hole pressure & Flow rate SCFt/D & Recovery factor \\
\hline 1 & 200 & 15434 & $71 \%$ \\
\hline 2 & 400 & 15434 & $72 \%$ \\
\hline 3 & 600 & 15434 & $73 \%$ \\
\hline 4 & 800 & 15434 & $74 \%$ \\
\hline 5 & 1000 & 15434 & $75 \%$ \\
\hline 6 & 1200 & 15434 & $76 \%$ \\
\hline 7 & 1500 & 15434 & $82 \%$ \\
\hline 8 & 2000 & 15434 & $69 \%$ \\
\hline
\end{tabular}

Table 3. Results of Sensitivity Analysis for WAG Ratio.

\begin{tabular}{|c|c|c|c|}
\hline Scenario no & WAG ratio & Water injection rate (BLL/D) & RF\% \\
\hline 1 & $1: 1$ & 5132 & $68 \%$ \\
\hline 2 & $1: 2$ & 2566 & $63 \%$ \\
\hline 3 & $1: 4$ & 1283 & $60 \%$ \\
\hline 4 & $2: 1$ & 10528 & $80 \%$ \\
\hline 5 & $3: 1$ & 15000 & $82 \%$ \\
\hline 6 & $4: 1$ & 20530 & $79 \%$ \\
\hline 7 & CGI & 0 & $82 \%$ \\
\hline
\end{tabular}

Table 4. Results Of Sensitivity Analysis for WAG Cycle.

\begin{tabular}{|c|c|c|}
\hline Scenarios & Cycle duration & RF \\
\hline 1 & 6 months & $78.5 \%$ \\
\hline 2 & 1 year & $82 \%$ \\
\hline 3 & 1.5 year & $79 \%$ \\
\hline 4 & 2 year & $80.7 \%$ \\
\hline 5 & 3 year & $81.1 \%$ \\
\hline 6 & 4 year & $85.3 \%$ \\
\hline 7 & 5 year & $86.6 \%$ \\
\hline
\end{tabular}


Cumulative Gas Injection: Figure 4 shows the difference of cumulative gas injection during continues $\mathrm{CO}_{2}(\mathrm{CGS})$ and WAG $\mathrm{CO}_{2}$ injection. The cumulative gas injection during the CGS is much higher than WAG injection. Thus, WAG reduced costs for project, Injection of $\mathrm{WAG} \mathrm{CO}_{2}$ gas, with the resulting decrease gas injection relative to the base forecast will cause reduced gas production over time. Also WAG injection reduced future costs/penalties associated with handling of gas injected volume. WAG injection increased capacity for oil, liquid capacity limited. If this capacity constraint continues, we should see an increased capacity for oil with a reduction of produced gas. This will allow further acceleration of oil recovery if the base forecast is total liquid constrained.

Pressure Maintenance During WAG Injection: Figure 5 shows how the WAG injection will maintain the reservoir pressure, during $\mathrm{CO}_{2}$ injection the reservoir pressure is direct proportional with time. While during the WAG injection, the period of the water injection will maintain the reservoir pressure, which will help the reservoir pressure to keep above the minimum miscibility pressure.

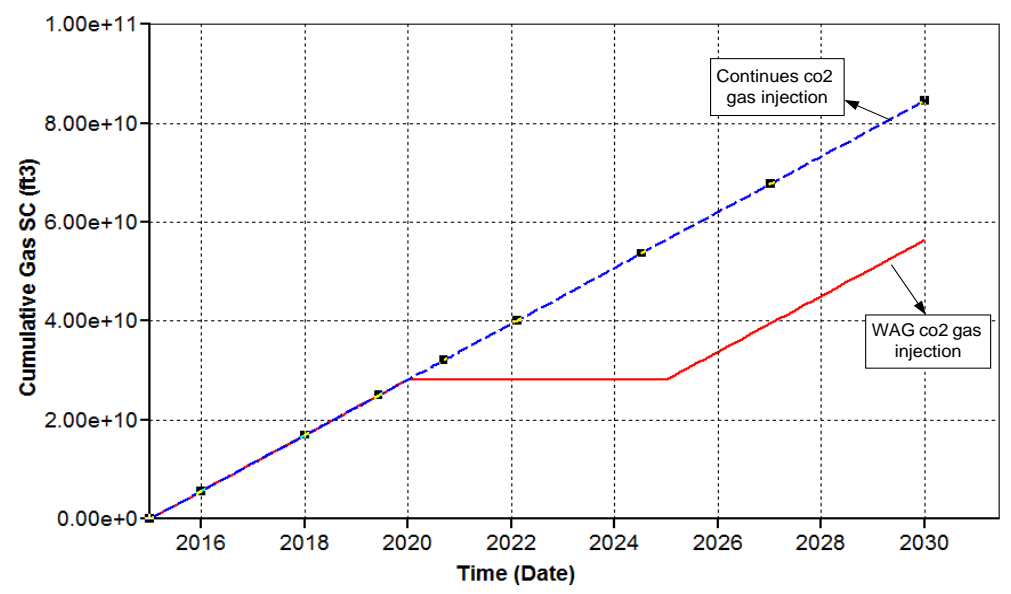

Figure 4. The Difference of Cumulative Gas Injection during Continues $\mathrm{CO}_{2}$ and WAG.

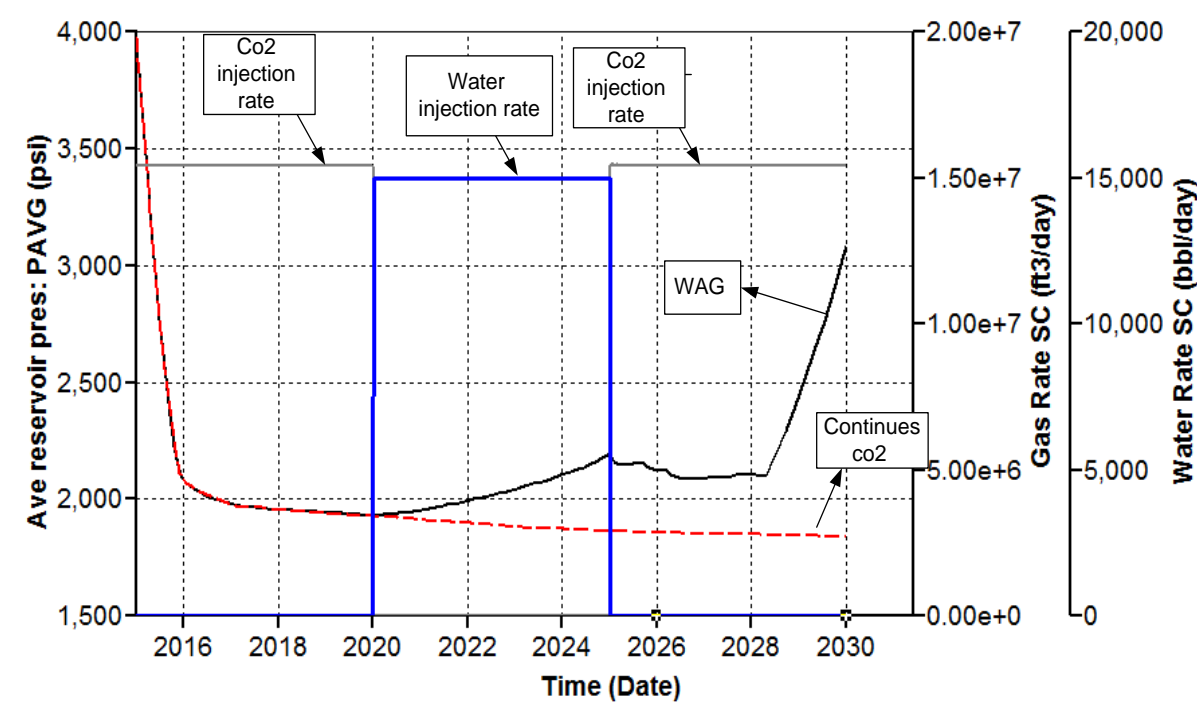

Figure 5. Shows How the WAG Injection Maintain the Reservoir Pressure.

\section{CONCLUSIONS}

1. Compositional simulation should be used to evaluate miscible injection process.

2. WAG provides high recovery for the $X$ field when compared with conventional methods due to high sweep efficiency. While, CGI gave a low recovery due to the gravity segregation affect.

3. There are some consideration should be taken in the account during WAG injection project such as sensitivity analysis and availability of the gas. 
4. In this field the bottom hole pressure at 1500 Psia gave a high recovery factor than lower $\mathrm{P}_{\mathrm{wf}}$, this indicated that the $\Delta P$ between the reservoir pressure and pwf play an important factor to get the miscibility, if the gain between the reservoir pressure and pwf is hug. That will deplete the energy inside the reservoir and the energy inside the reservoir will be quickly depleted. There is adapt point between the $\Delta P$ and energy inside the reservoir, it should be obtained to get the better understanding of the reservoir mechanism. Several improvements of this work can be made in order to expand the applicability of the development, such as:

5. Forecast the economic performance of WAG implementation.

6. Infill many of producer and injector wells would also be a valuable improvement for future studies.

\section{REFERENCES}

Don W. Green, G. Paul Willhite. 1998. Enhanced Oil Recovery. Henry L. Doherty Memorial Fund of AIME, Society of Petroleum Engineers.

Samba, Mohammed A. Zuher Syihab.2020. Development Of A Predictive Model For Enhanced Oil Recovery Water Alternating Gas Injection Using Proxy Model Derived From Artificial Neural Network. Institut Teknologi Bandung.

Shetty, Shrinidhi. 2011. Evaluation Of Simultaneous Water And Gas Injection Using CO2.

Teknick petroleum services ltd, Enhanced Oil Recovery, suite 2500, 530 - 8th Avenue S.W. Calgary, Aiberta T2P 3S8, june 2001.

U.S Department of Energy. (2013, August). Retrieved from "http://energy.gov/fe/science-innovation/oil-gas/enhancedoil-recovery" 